\title{
Three new species and one new record of the genus Siphunculina from China (Diptera, Chloropidae)
}

\author{
Xiao-Yan Liu', Emilia P. Nartshuk², Ding Yang ${ }^{3}$ \\ I Hubei Insect Resources Utilization and Sustainable Pest Management Key Laboratory, College of Plant \\ Science and Technology, Huazhong Agricultural University, Wuhan 430070, China 2 Zoological Institute, \\ Russian Academy of Sciences, St. Petersburg 199034, Russia 3 Department of Entomology, China Agricultural \\ University, Beijing 100193, China
}

Corresponding author: Xiao-Yan Liu (yanziliu52@163.com)

Academic editor: R. Meier | Received 9 April 2017 | Accepted 21 June 2017 | Published 2 August 2017

http://zoobank.org/249E015E-F9DB-42CA-8C49-1BF26A60378E

Citation: Liu X-Y, Nartshuk EP, Yang D (2017) Three new species and one new record of the genus Siphunculina from China (Diptera, Chloropidae). ZooKeys 687: 73-88. https://doi.org/10.3897/zookeys.687.13156

\begin{abstract}
Three new species of the genus Siphunculina Rondani from China, S. bulbifera sp. n., S. scalpriformis sp. n., and $S$. shangyongensis sp. n., are described and illustrated. One species, S. funicola (de Meijere), is reported from China for the first time. A key to the species of genus Siphunculina from China is given.
\end{abstract}

\section{Keywords}

China, Chloropidae, Diptera, new species, Siphunculina, Taxonomy

\section{Introduction}

The genus Siphunculina was erected by Rondani (1856). It belongs to the Aphanotrigonum genus group of the subfamily Oscinellinae (Andersson 1977). There are 34 species known from the world, of which 17 species are distributed in the Oriental Region, ten species in the Palaearctic Region, eleven species in the Afrotropical, three species in the Australian, only one species is known to occur in the Nearctic and Neotropical Regions (Cherian 1970, 1977; Sabrosky 1977, 1980, 1989; Kanmiya 1982, 1989, 1994; Nartshuk 1984, 2005, 2007; Ismay and Nartshuk 2000; Merz 2008; Iwasa et al. 2013). Adults of some species are attracted to decaying

Copyright Xiao-Yan Liu et al. This is an open access article distributed under the terms of the Creative Commons Attribution License (CC BY 4.0), which permits unrestricted use, distribution, and reproduction in any medium, provided the original author and source are credited. 
meat, wounds, scratches, mucous membranes, eyes, lips, moist skin, in-between toes, sweat, and other secretions of the body and are suspected of mechanically transmitting pathogenic organisms to man and domestic animals (Graham-Smith 1930; Chansang et al. 2010). The larvae can be found in birds' nests, excrement, or dead animals, which are saprophilous or scatophagous (Kanmiya 1983; Ferrar 1987; Ismay and Nartshuk 2000).

To date, five species are known to occur in China, of which four are known from Taiwan and two species are distributed in mainland China. In this paper, three new species of the genus Siphunculina from China, S. bulbifera sp. n., S. scalpriformis sp. n. and $S$. shangyongensis sp. n., are described and illustrated. One species, S. funicola (de Meijere), is newly recorded from China. A key to the species of genus Siphunculina from China is given.

\section{Materials and methods}

Specimens were studied and illustrated with ZEISS Stemi 2000-c. Genitalic preparations were made by macerating the apical portion of abdomen in warm $10 \% \mathrm{NaOH}$ for 17-20 min, after examination it was transferred to fresh glycerine and stored in a microvial pinned below the specimen. Specimens are deposited in the Entomological Museum of China Agricultural University (CAU), Beijing. The morphological nomenclature follows Cumming and Wood (2009). The following abbreviations are used:

$\begin{array}{llll}\text { bas } & \text { basiphallus; } & \text { gon } & \text { gonite; } \\ \text { cerc } & \text { cercus; } & \text { hyp } & \text { hypandrium; } \\ \text { dis } & \text { distiphallus; } & \text { phal } & \text { phallapodeme; } \\ \text { dm-cu discal medial-cubital crossvein; } & \text { r-m } & \text { radio-medial crossvein; } \\ \text { ep } & \text { epandrium; } & \text { sur } & \text { surstylus. }\end{array}$

\section{Taxonomy}

\section{Family Chloropidae}

\section{Genus Siphunculina Rondani, 1856}

Siphunculina Rondani, 1856: 128. Type species: Siphunculina brevinervis Rondani, 1856 (= Siphonella aenea Macquart, 1835), by original designation.

Microneurum Becker, 1903: 152. Type species: Microneurum maculifrons Becker, 1903 (= Oscinis ornatifrons Loew, 1858), by monotypy.

Liomicroneurum Enderlein, 1911: 230. Type species: Siphonella funicola de Meijere, 1905 , by original designation. 
Diagnosis. Head with vibrissal angle more or less distinctly produced beyond eye; face with deeply concave antennal foveae and a distinct median carina reaching epistoma; cephalic setae and setulae generally short; wing with veins $\mathrm{R}_{1}$ and $\mathrm{R}_{2+3}$ extremely closed on basal portion, vein $\mathrm{R}_{2+3}$ very short, length of $2 \mathrm{nd}$ costal sector extremely shorter than the 3rd sector; femoral and tibial organs absent (Kanmiya 1983, 1994).

Distribution. Widespread world-wide distribution, see Nartshuk (2012). China: Beijing, Zhejiang, Hainan, Guizhou, Yunnan, Taiwan.

\section{Key to species of Siphunculina from China}

$1 \quad$ Cephalic setae and setulae black or brown......................................... 2

- Cephalic setae and setulae light yellow or yellow ....................................

2 Ocellar triangle shiny except for ocellar tubercle, without microtomentum; frons, ocellar triangle and scutum marked out by reticulate patterns with alternating microtomentose and bare maculae...... S. striolata (Wiedemann)

- $\quad$ Ocellar triangle not entirely shiny, partly or entirely microtomentose; frons, ocellar triangle and scutum not marked out by alternating microtomentose and bare maculae ........................................................................ 3

3 Notopleurals 1+2; apical scutellar seta as long as scutellum (Fig. 20)

S. funicola (de Meijere)

- $\quad$ Notopleurals 1+1; apical scutellar seta shorter than scutellum ...................4

4 Two pairs of scutellar setae; 3rd costal sector 2 times as long as 2nd sector (Fig. 2).

S. bulbifera sp. $\mathrm{n}$. Three pairs of scutellar setae; 3rd costal sector 3-4 times as long as 2nd sector ... 5 Ocellar triangle nearly or completely reaching anterior margin of frons, with a median groove.

S. nitidissima Kanmiya Ocellar triangle ending slightly but distinctly before anterior margin of frons, without median groove .. 6 Hind tibia yellow with largely infuscate maculae medially; tarsi entirely yellow; surstylus as long as the epandrium in lateral view ...... S. bella Kanmiya Hind tibia yellow except for middle $1 / 3$ brown; tarsi yellow except for hind tarsomeres 2-4 brown; surstylus 0.6 times as long as the epandrium in lateral view (Figs 13, 16)

S. shangyongensis sp. $\mathrm{n}$.

$7 \quad$ Ocellar triangle extending to middle or slightly over middle of frons ...... .. 8 Ocellar triangle extending near or completely to anterior margin of frons.....

S. minima (de Meijere)

Ocellar triangle microtomentose except for area in front of ocelli and on both sides of ocellar tubercle shiny (Fig. 8) S. scalpriformis sp. $\mathbf{n}$. Ocellar triangle shiny with 2 microtomentose patches extending from nearly mediolateral of triangle to anterior ocellus S. fasciata Cherian 


\section{Siphunculina bulbifera sp. $\mathrm{n}$.}

http://zoobank.org/2A36E011-58B7-47A8-9B00-BEABB0027FFE

Figs 1-6

Diagnosis. Ocellar triangle smooth, shiny, reaching anterior margin of frons, with pointed apex. Scutellum with two pairs of scutellar setae on small tubercles. Cephalic and thoracic setae and setulae black. Notopleurals $1+1$. Distal 2/3 of gonite long globose.

Description. Holotype. Male. Body length $2.2 \mathrm{~mm}$, wing length $1.6 \mathrm{~mm}$.

Head black, 0.8 times as long as high in profile, as wide as thorax; face somewhat concave in lateral view, facial carina distinct, broad; frons as long as wide, projecting slightly in front of eye; gena broad, 0.5 times as wide as first flagellomere; parafacial linear; vibrissal angle distinctly produced beyond eye by subequal length to gena-width. Ocellar triangle smooth, shiny, reaching anterior margin of frons, with pointed apex; ocellar tubercle black. Cephalic setae and setulae black. Antenna yellow except for distodorsal $1 / 2$ of first flagellomere brown, with thick grayish microtomentum; first flagellomere 0.6 times as long as wide; arista black except for basal segment yellow, with short pubescence. Proboscis brown to yellow with yellow setulae; palpus brown to yellow with yellow setulae.

Thorax black with gray microtomentum, evenly covered with short setulae. Scutum as long as wide. Thoracic pleuron shiny black. Scutellum 0.55 times as long as wide; two pairs of scutellar setae on small tubercles; apical scutellar seta short, 0.3 times as long as scutellum. Setae and setulae on thorax black; notopleurals 1+1, developed. Legs brown except for basal portion and distal $1 / 3$ of fore tibia, both ends of mid and hind tibiae, fore and hind tarsomeres 1, mid tarsomeres 1-2 yellow. Setulae on legs brown. Wing 2.3 times as long as wide, hyaline; veins yellowish brown. Relative lengths of 2 nd $: 3 \mathrm{rd}: 4$ th costal sections $=5: 10: 3$; cross-veins $\mathrm{r}-\mathrm{m}$ and dm-cu not approximated, $\mathrm{r}-\mathrm{m}$ at basal 0.65 of discal medial cell. Halter brown.

Abdomen shiny brown except for tergite 1 yellow with brown distally; venter yellow. Setulae on abdomen black.

Male genitalia (Figs. 3-6): Epandrium blackish brown with long brown setulae; surstylus distinctly shorter than epandrium in lateral view. Cercus short and broad, with moderately concave ventral margin in dorsal view. Pre- and postgonites fused, basal 1/3 narrow, distal 2/3 long globose; basiphallus longer than wide, cylindrical; distiphallus short, membranous; phallapodeme long, with basal stalk narrow in lateral view. Hypandrium broad, with two basal rounded projections, arms free and short, apex with internal projection long, external projection short.

Female. Unknown.

Type material. Holotype, $\widehat{\jmath}$, China: Beijing: Shidu, 1-2. VI. 2009, leg. Dan Zhou (photographed and genitalia prepared). Paratype, $2 \widehat{\partial} \sigma^{\lambda}$, same locality as holotype, 1-2. VII. 2009, leg. Jinjing Wang (in 75\% alcohol, deposited in CAU).

Distribution. China (Beijing). 

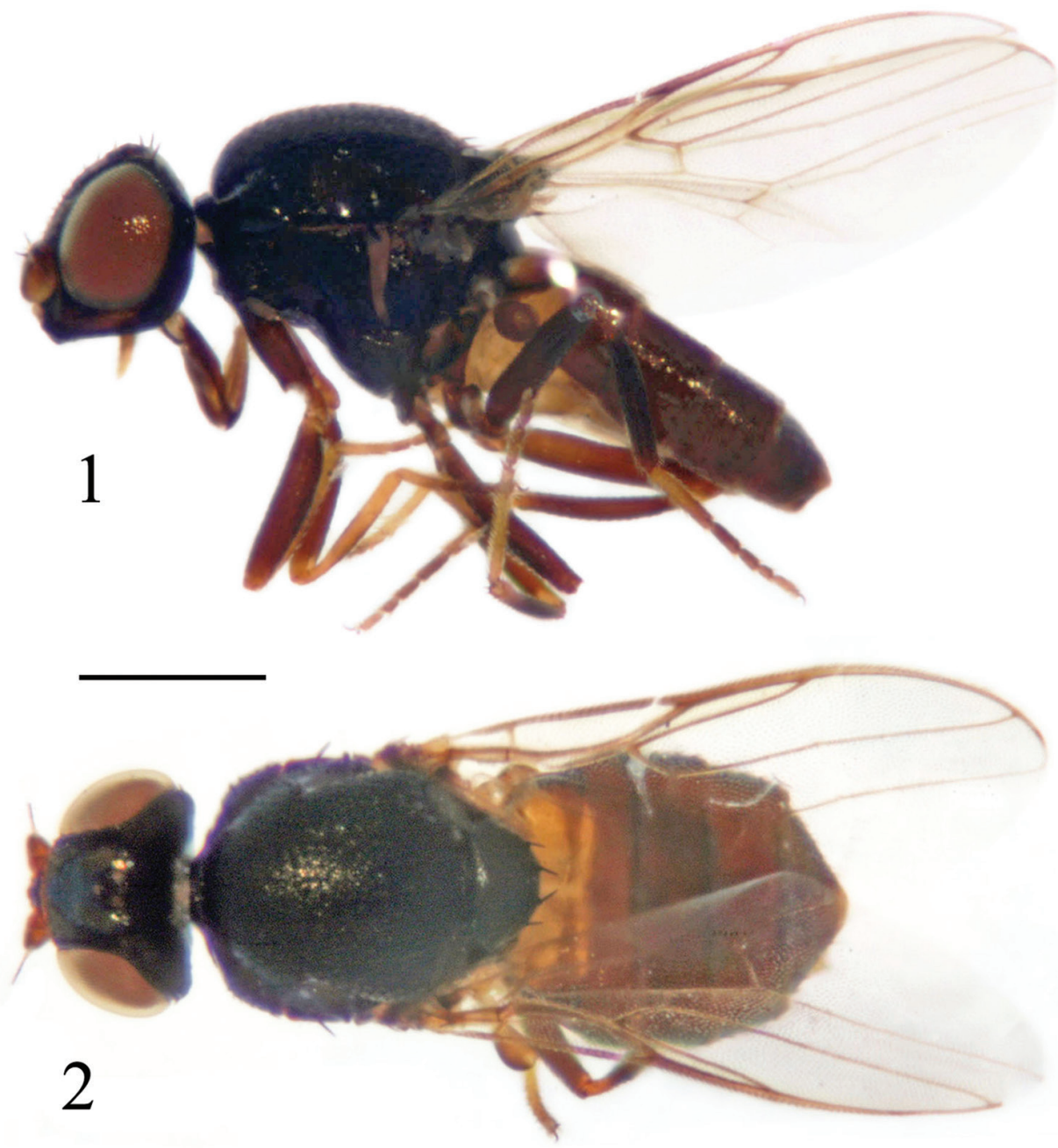

Figures I-2. Siphunculina bulbifera sp. n., holotype. habitus, I lateral view $\mathbf{2}$ dorsal view. Scale bar $0.05 \mathrm{~mm}$.

Remarks. The new species is somewhat similar to S. nitidissima Kanmiya, but can be separated from the latter by the following features: ocellar triangle smooth without median groove, two pairs of scutellar setae on small tubercles, and gonite has narrow base, its distal 2/3 long and globose; in S. nitidissima, the ocellar triangle has a median groove, the scutellum has three pairs of scutellar setae on small tubercles, and the gonite is finger-like (Kanmiya 1982).

Etymology. The specific name is from the Latin bulbifera ("bulbiform"), referring to the shape of gonite. 

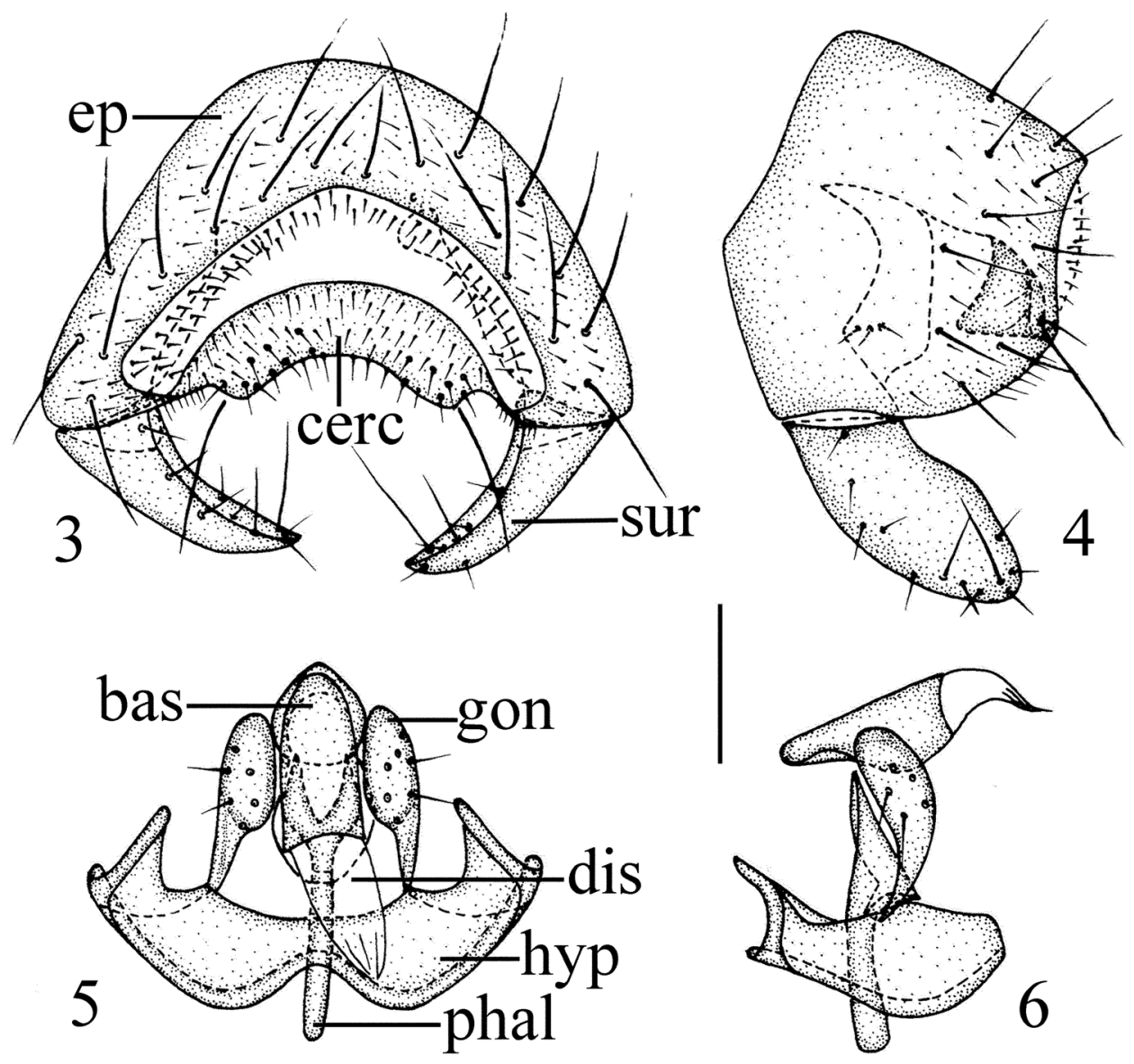

Figures 3-6. Siphunculina bulbifera sp. n., holotype. 3 epandrium, posterior view $\mathbf{4}$ epandrium, lateral view $\mathbf{5}$ hypandrium and phallic complex, ventral view $\mathbf{6}$ hypandrium and phallic complex, lateral view. Scale bar: $0.1 \mathrm{~mm}$.

\section{Siphunculina scalpriformis sp. $\mathbf{n}$.}

http://zoobank.org/3DFBB88D-1403-4FD0-92D6-02AEC4090064

Figs $7-12$

Diagnosis. Ocellar triangle black with gray microtomentum except for area in front of ocelli and on both sides of ocellar tubercle shiny, reaching anterior 0.6 of frons. Scutellum with three pairs of scutellar setae. Cephalic and thoracic setae and setulae yellow. Notopleurals 1+1. Gonite knife-like, incised on basal 1/3 of each inner margin.

Description. Holotype. Male. Body length 1.9-2.0 mm, wing length 1.5-1.6 mm.

Head black with gray microtomentum, 0.7 times as long as high in profile, as wide as thorax; face somewhat concave in lateral view, facial carina narrow; frons 0.9 times 


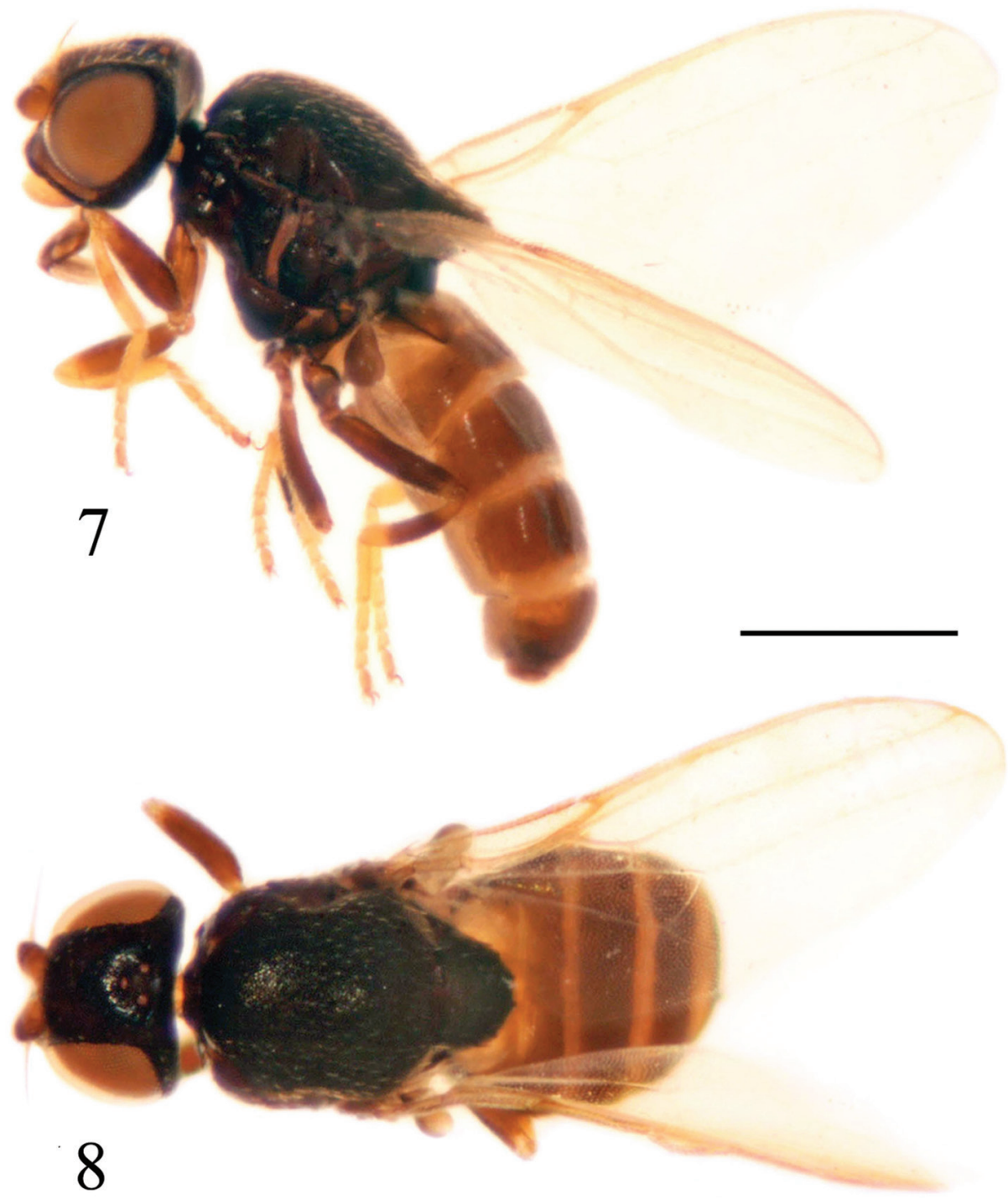

Figures 7-8. Siphunculina scalpriformis sp. n., holotype. habitus 7 lateral view 8 dorsal view. Scale bar $0.05 \mathrm{~mm}$.

as long as wide, projecting slightly in front of eye; gena yellow except for ventral $1 / 3$ black, broad, 0.5 times as wide as first flagellomere; parafacial linear; vibrissal angle weakly produced beyond eye. Ocellar triangle partly microtomentose, area in front of ocelli and on both sides of ocellar tubercle shiny, its apex reaching anterior 0.6 of frons, with slightly pointed apex; ocellar tubercle black. Cephalic setae and setulae yellow. Antenna yellow except for dorsal margin of first flagellomere brown, with thick grayish microtomentum; first flagellomere 0.75 times as long as wide; arista black except for 

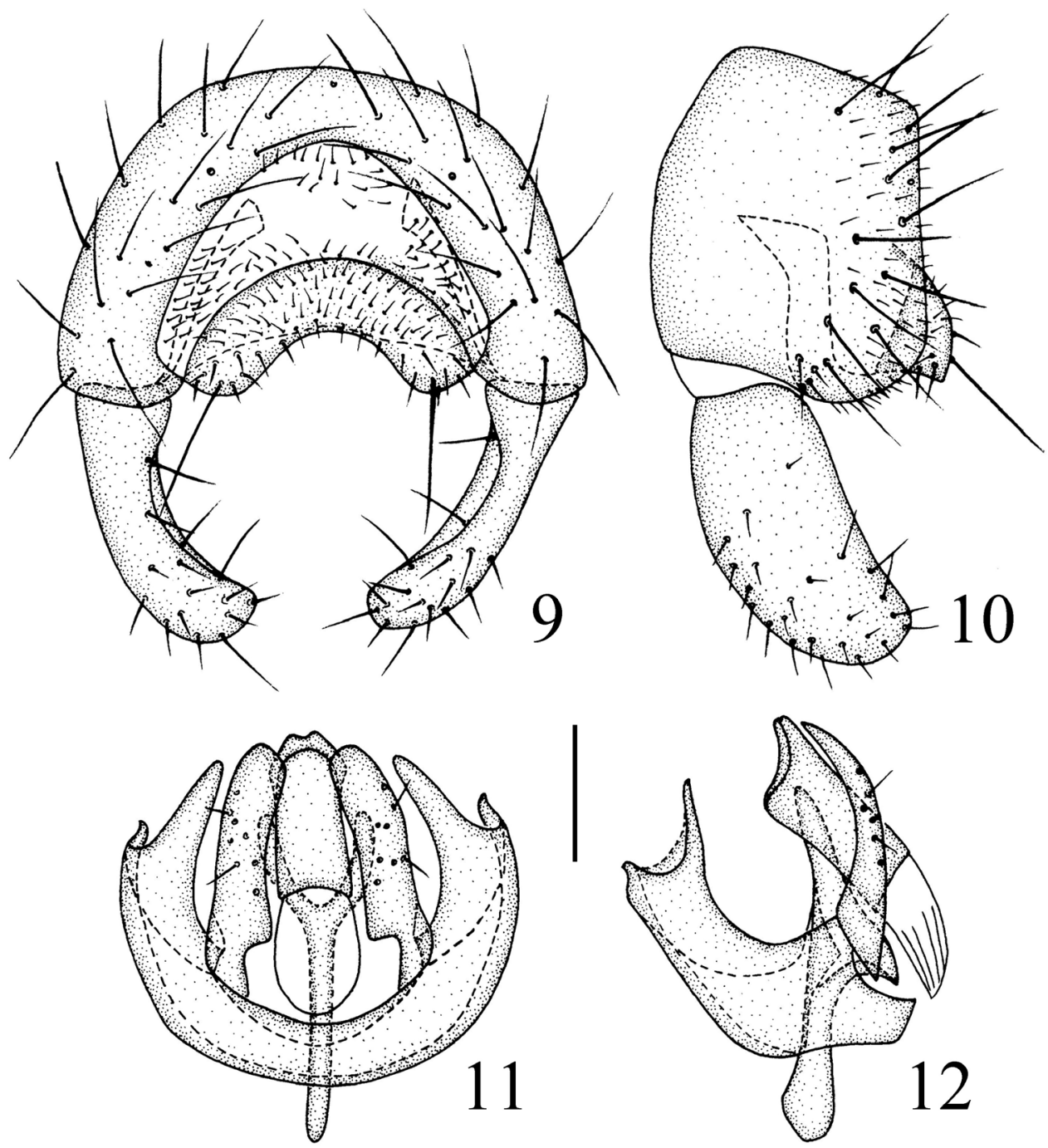

Figures 9-12. Siphunculina scalpriformis sp. n., holotype. $\mathbf{9}$ epandrium, posterior view $\mathbf{I} \mathbf{0}$ epandrium, lateral view II hypandrium and phallic complex, ventral view $\mathbf{2}$ hypandrium and phallic complex, lateral view. Scale bar: $0.1 \mathrm{~mm}$.

basal segment brownish, with short pubescence. Proboscis black to yellowish brown with yellow setulae; palpus yellow with yellow setulae.

Thorax black with gray microtomentum, evenly covered with short setulae. Scutum as long as wide. Thoracic pleuron shiny black without microtomentum. Scutellum 0.6 times as long as wide; 3 pairs of scutellar setae on small tubercles; apical scutellar seta short, 0.5 times as long as scutellum. Setae and setulae on thorax yellow; notopleurals $1+1$, developed. Legs with coxae black, femora black with distal tips yellow, fore tibia yellow with weakly infuscated medially, mid and hind tibiae black with both tips yel- 
low, tarsi yellow. Setulae on legs yellow. Wing 2.2 times as long as wide, hyaline; veins brownish. Relative lengths of $2 \mathrm{nd}: 3 \mathrm{rd}: 4$ th costal sections $=6: 17: 4$; cross-veins $\mathrm{r}-\mathrm{m}$ and $\mathrm{dm}$-cu not approximated, $\mathrm{r}-\mathrm{m}$ at basal 0.65 of discal medial cell. Halter brown.

Abdomen shiny brown; venter yellow. Setulae on abdomen black.

Male genitalia (Figs. 9-12): Epandrium blackish brown with long brown setulae; surstylus as long as epandrium in lateral view. Cercus short and broad, with moderately concave ventral margin in dorsal view. Pre- and postgonites fused, knife-like, incised on basal $1 / 3$ of each inner margin; basiphallus longer than wide, cylindrical; distiphallus short, membranous; phallapodeme long, with basal stalk narrow in lateral view. Hypandrium broad, without two basal rounded projections, arms free and long, apex with internal projection long, external projection short.

Female. Unknown.

Type material. Holotype, $\widehat{O}$, China: Guizhou: Maolan, Yaoqu, 30. V. 2010, leg. Dan Zhou (photographed and genitalia prepared). Paratype, $2 \widehat{\partial}$, same data as holotype (in 75\% alcohol, deposited in CAU).

Distribution. China (Guizhou).

Remarks. The new species is somewhat similar to $S$. minima (de Meijere), but can be separated from the latter by the following features: ocellar triangle reaching anterior 0.6 of frons, gena 0.5 times as wide as first flagellomere; in S. minima, the ocellar triangle reaches anterior 0.9 of frons, the gena is as wide as the first flagellomere (Kanmiya 1982).

Etymology. The specific name is from the Latin scalpriformis ("knife-like"), referring to the shape of gonite.

\section{Siphunculina shangyongensis sp. $\mathrm{n}$.}

http://zoobank.org/67F6EFAD-6BE8-4820-B886-7A39745E3727

Figs 13-18

Diagnosis. Ocellar triangle black, smooth, shiny, reaching anterior 0.9 of frons, with slightly pointed apex. Scutellum with three pairs of scutellar setae on small tubercles. Cephalic and thoracic setae and setulae black. Notopleurals 1+1. Gonite nearly rectangular, slightly narrowed basally.

Description. Holotype. Male. Body length $1.8 \mathrm{~mm}$, wing length $1.6 \mathrm{~mm}$.

Head black with gray microtomentum, 0.75 times as long as high in profile, as wide as thorax; face somewhat concave in lateral view, facial carina distinct; frons brown, 0.9 times as long as wide, projecting only slightly in front of eye; gena broad, 0.5 times as wide as first flagellomere, yellowish brown except for ventral margin black; parafacial indistinct; vibrissal angle distinctly produced beyond eye by subequal length to gena-width. Ocellar triangle black, smooth, shiny, reaching anterior 0.9 of frons, with slightly pointed apex; ocellar tubercle brown. Cephalic setae and setulae black. Antenna yellow with thick grayish microtomentum except for distodorsal margin of first flagellomere black; first flagellomere as long as wide; arista black except for basal 


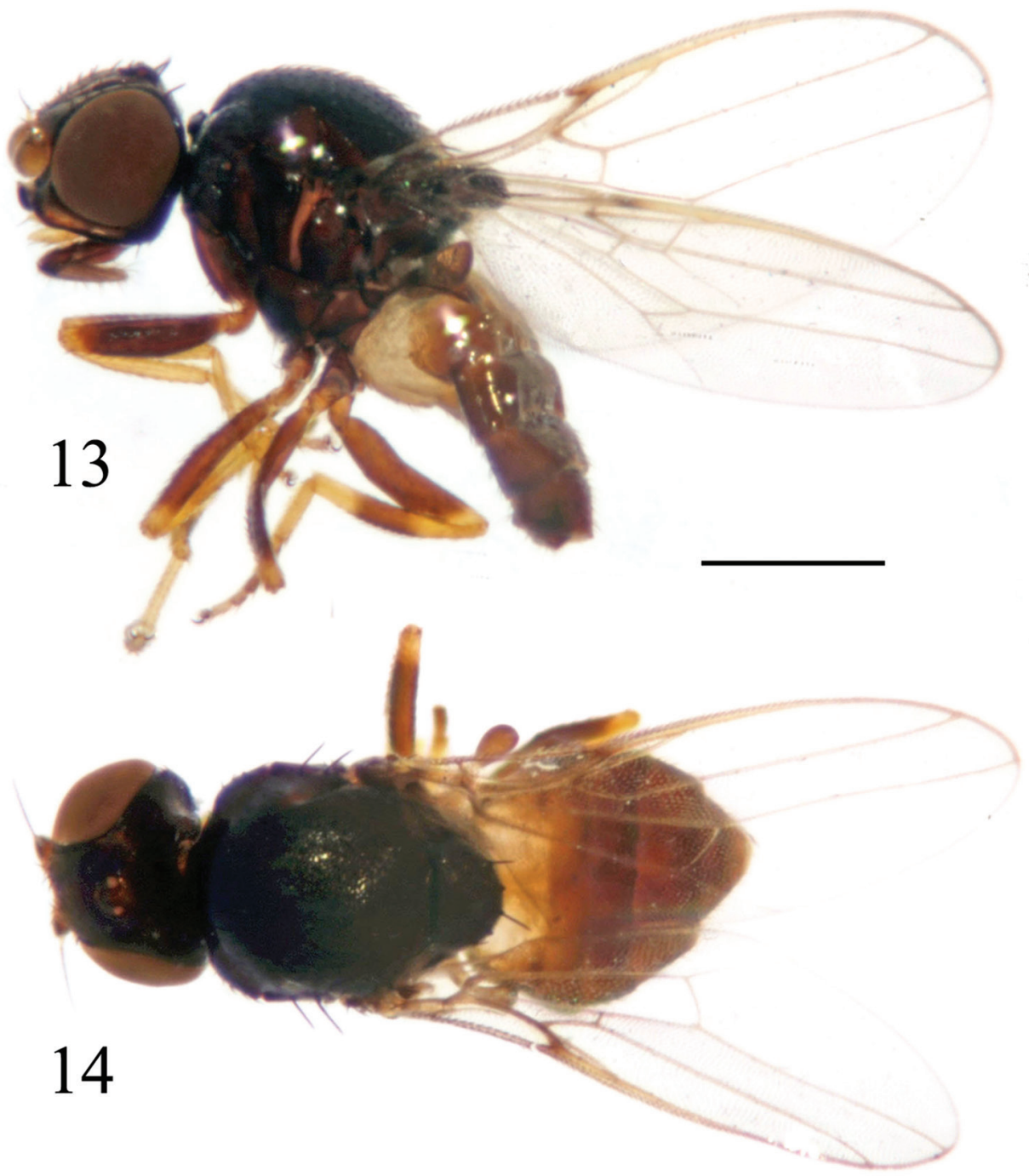

Figures 13-14. Siphunculina shangyongensis sp. n., holotype. habitus, $\mathbf{3}$ lateral view $\mathbf{1 4}$ dorsal view. Scale bar: $0.05 \mathrm{~mm}$.

segment yellow, with short brown pubescence. Proboscis brown with brown setulae; palpus yellow with brown setulae.

Thorax black, evenly covered with short setulae. Scutum 1.1 times as long as wide. Thoracic pleuron shiny brown without microtomentum. Scutellum black, 0.6 times as long as wide; 3 pairs of scutellar setae on small tubercles; apical scutellar seta 0.5 times as long as scutellum. Setae and setulae on thorax black; notopleurals $1+1$, developed. Legs with coxae brown, femora brown with distal tips yellow, tibiae yellow with middle $1 / 3$ of mid tibia brownish, middle $1 / 3$ of hind tibia brown, tarsi yellow with hind 


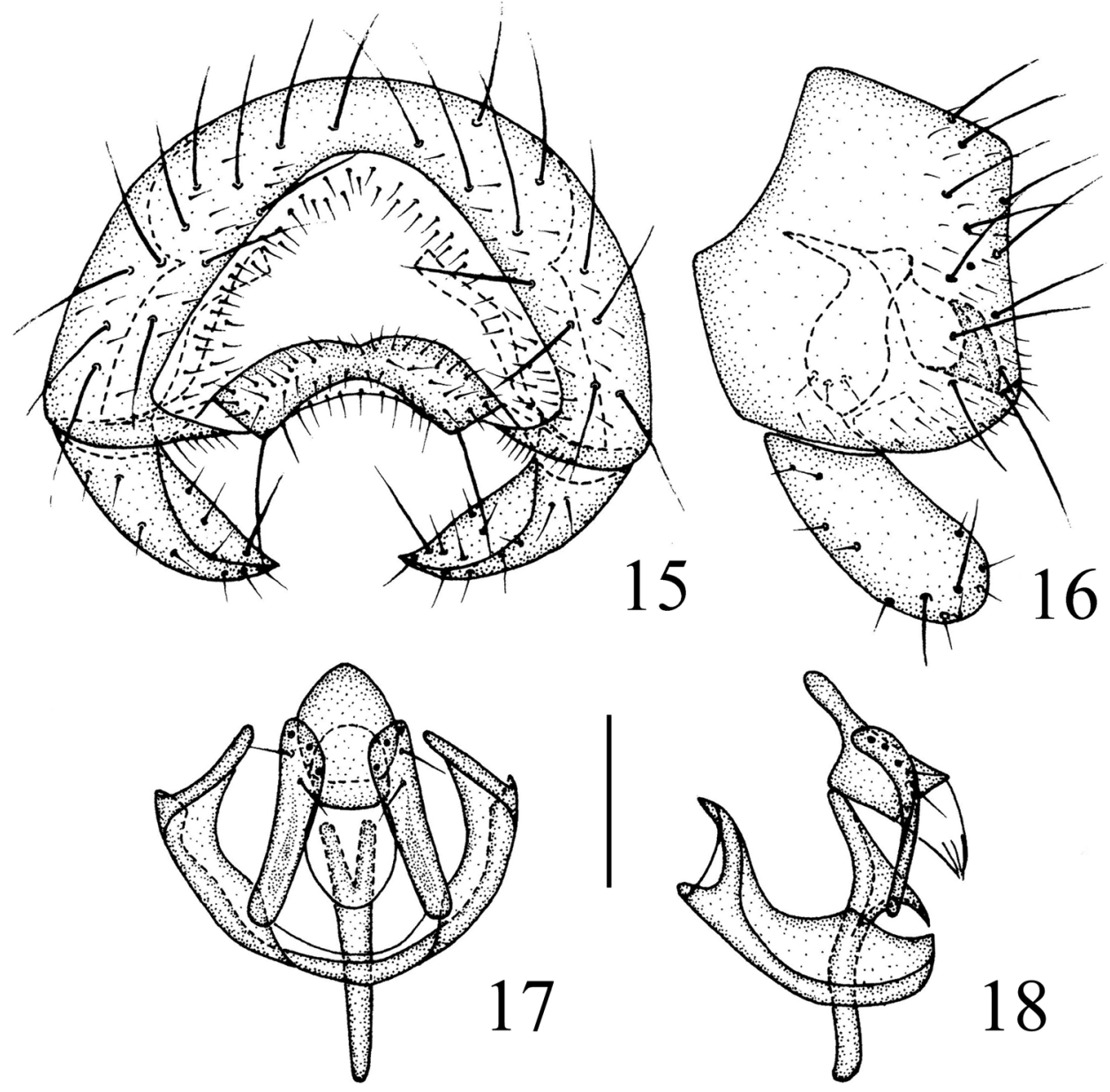

Figures 15-18. Siphunculina shangyongensis sp. n., holotype. $\mathbf{5}$ epandrium, posterior view $\mathbf{1 6}$ epandrium, lateral view $\mathbf{I 7}$ hypandrium and phallic complex, ventral view $\mathbf{I} 8$ hypandrium and phallic complex, lateral view. Scale bar: $0.1 \mathrm{~mm}$.

tarsomeres 2-4 brown. Setulae on legs brown. Wing 2.2 times as long as wide, hyaline; veins yellowish brown. Relative lengths of $2 \mathrm{nd}: 3 \mathrm{rd}: 4$ th costal sections $=3: 11: 3$; cross-veins $\mathrm{r}-\mathrm{m}$ and $\mathrm{dm}-\mathrm{cu}$ not approximated, $\mathrm{r}-\mathrm{m}$ at basal 0.6 of discal medial cell. Halter brown.

Abdomen shiny brown except for tergite 1 yellow; venter yellow. Setulae on abdomen black.

Male genitalia (Figs. 15-18): Epandrium blackish brown with long brown setulae; surstylus 0.6 times as long as epandrium in lateral view. Cercus short and broad, with a concavity on ventral margin. Gonite nearly rectangular, slightly narrowed basally; basiphallus slightly longer than wide, cylindrical; distiphallus short, membranous; phallapodeme long, distinctly projecting beyond hypandrium, with basal stalk narrow in 
lateral view. Hypandrium narrow, without two basal rounded projections, arms free and long, apex with internal projection long, external projection short.

Female. Unknown.

Type material. Holotype, $\widehat{\jmath}$, China: Yunnan: Xishuangbanna, Shangyong, 7. V. 2007, leg. Wenliang Li (photographed and genitalia prepared). Paratype, $3 \AA \widehat{\jmath}$, same locality and date as holotype, leg. Hui Dong (in 75\% alcohol, deposited in CAU).

Distribution. China (Yunnan).

Remarks. The new species is somewhat similar to $S$. bella Kanmiya, but can be separated from the latter by the following features: hind tibia yellow except for middle $1 / 3$ brown, tarsi yellow except for hind tarsomeres 2-4 brown, surstylus 0.6 times as long as epandrium in lateral view; in $S$. bella, the hind tibia is yellow with largely infuscate maculae medially, the tarsi are entirely yellow, the surstylus is as long as epandrium in lateral view (Kanmiya 1989).

Etymology. The species is named after the type locality Shangyong.

\section{Siphunculina funicola (de Meijere, 1905)}

Figs 19-24

Siphonella funicola de Meijere, 1905: 160. Type locatity: Indonesia (Java).

Microneurum funicolum Becker, 1911: 141.

Liomicroneurum funicolum Duda, 1934: 112.

Siphunculina funicola (de Meijere): Becker et de Meijere, 1913: 303; de Meijere, 1918:

340; Sabrosky, 1977: 300; Cherian, 1977: 364; Kanmiya, 1989: 68.

Diagnosis. Frons black with gray microtomentum. Ocellar triangle entirely shiny black with a broad median groove, reaching anterior margin of frons, with slightly pointed apex. Gena broad, 0.5 times as wide as first flagellomere. Antenna yellow except for dorsal margin of first flagellomere brown; arista with short pubescence. Thorax black with gray microtomentum. Scutellum with 4 pairs of scutellar setae on small tubercles. Cephalic and thoracic setae and setulae black; notopleurals $1+2$. Legs black except for fore tibia, both ends of mid and hind tibiae and all tarsi yellow. Male genitalia (Figs. 21-24): Surstylus shorter than epandrium in lateral view. Cercus 2 times as long as wide, deeply incised medially. Gonite long finger-like, basal $1 / 4$ distinctly incised.

Specimens examined. $2 \widehat{\jmath} \widehat{\jmath}$, China: Hainan: Baisha, Hongmao, 19. V. 2007, leg. Ding Yang, 1 đे, Hainan: Baisha, 22. V. 2007, leg. Kuiyan Zhang, 1 ô, Hainan: Baisha, Yacha orchard, 19. IV. 2009, leg. Shan Huo (photographed and genitalia prepared).

Distribution. China (Hainan); Cambodia, India, Indonesia, Malaysia, Sri Lanka, Vietnam, Thailand, Nepal.

Remarks. This species has been called the Oriental eye-fly, predominantly inhabiting in the East and South Asian countries. The flies mass around men and cattle 


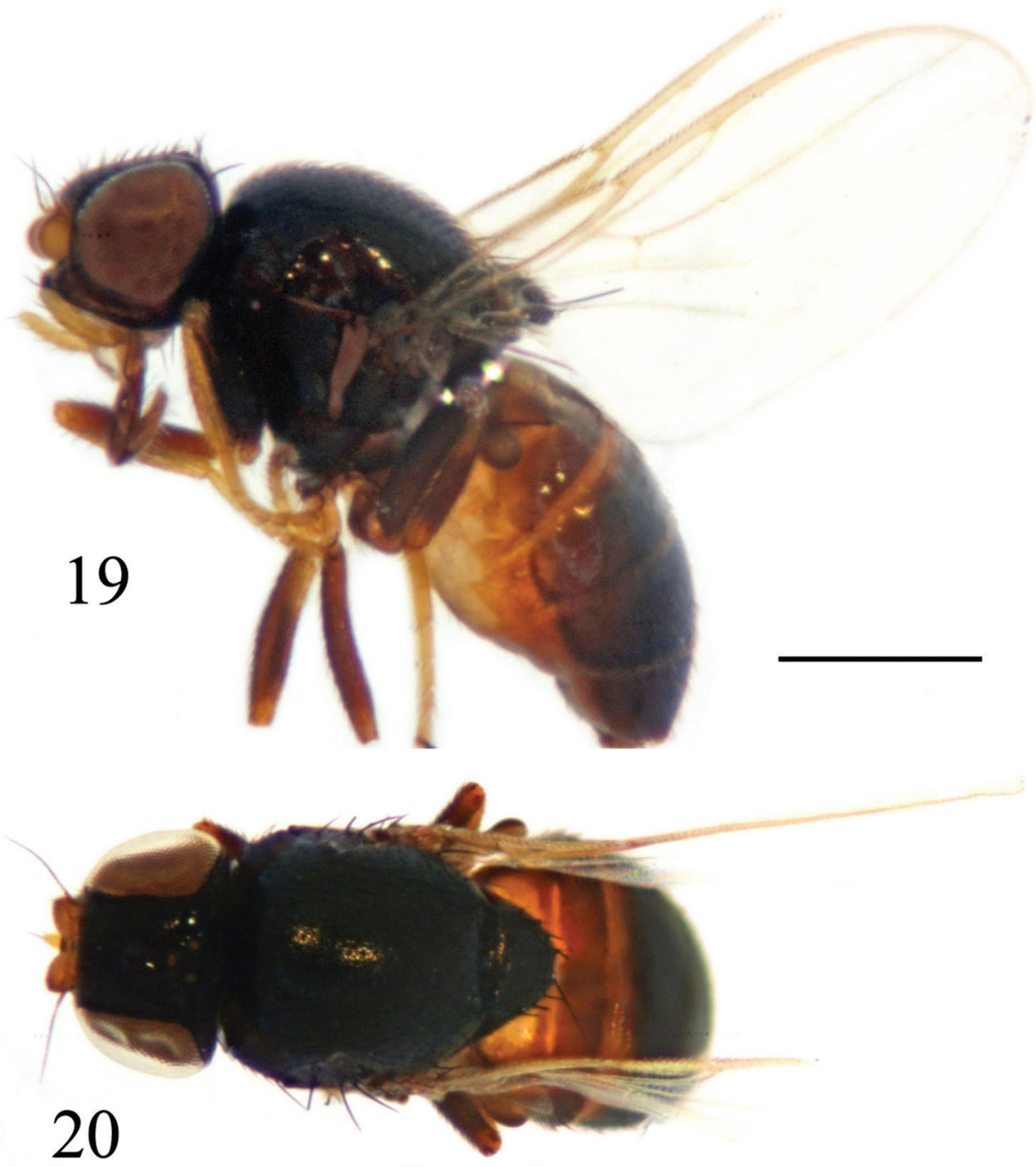

Figures 19-20. Siphunculina funicola (de Meijere), male. habitus 19 lateral view 20 dorsal view. Scale bar $0.05 \mathrm{~mm}$.

and cause considerable annoyance, and are responsible for spreading eye diseases. It is somewhat similar to $S$. ceylonica Kanmiya, but can be separated from the latter by the following features: ocellar triangle reaching anterior margin of frons, notopleurals $1+2$, apical scutellar seta as long as scutellum, cercus twice as long as wide, deeply incised medially; in S. ceylonica, ocellar triangle reaching anterior $4 / 5$ of frons, notopleurals $1+1$, apical scutellar seta much shorter than scutellum, cercus short, widely incised medially (Kanmiya 1989). 


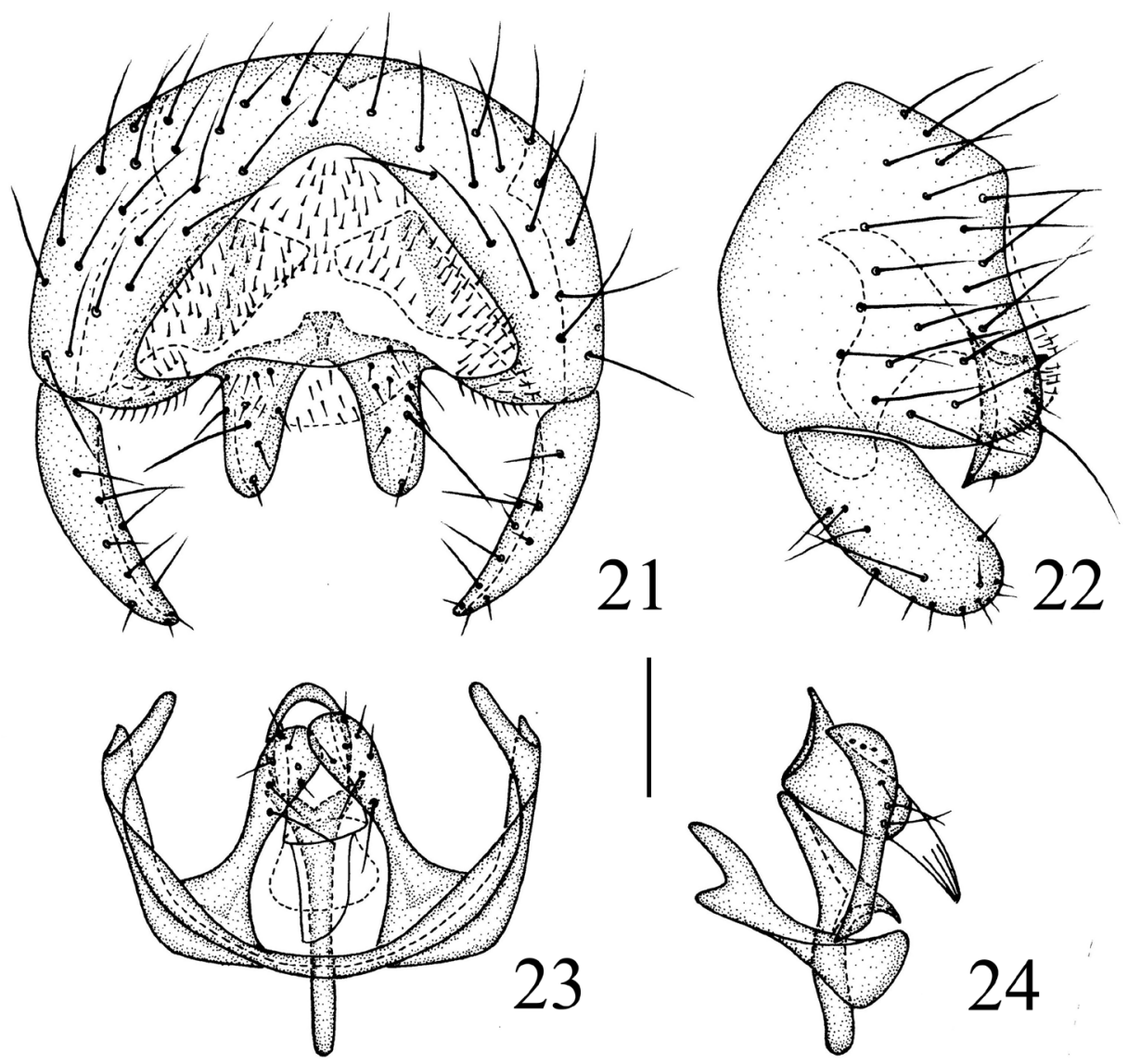

Figures 2I-24. Siphunculina funicola (de Meijere), male. $\mathbf{2} \mathbf{I}$ epandrium, posterior view $\mathbf{2 2}$ epandrium, lateral view $\mathbf{2 3}$ hypandrium and phallic complex, ventral view $\mathbf{2 4}$ hypandrium and phallic complex, lateral view. Scale bar: $0.1 \mathrm{~mm}$.

\section{Acknowledgements}

We are grateful to Dr. Kuiyan Zhang, Dr. Shan Huo and Dr. Jinjing Wang (Beijing), Dr. Hui Dong (Shenzhen), Dr. Wenliang Li (Luoyang) and Ms. Dan Zhou (Chenzhou) for collecting the specimens. Two anonymous reviewers are thanked for providing useful comments on an earlier draft of this paper. The research was funded by the National Natural Science Foundation of China (31301906) and the Russian State Project (01201351189) and RFFI (grant 15-54-53038).

\section{References}

Andersson H (1977) Taxonomic and phylogenetic studies on Chloropidae (Diptera) with special reference to Old World genera. Entomologica Scandinavica Supplementum 8: 1-200. 
Becker Th (1903) Aegyptische Dipteren. (Fortsetzung und Schluss). Mitteilungen aus dem Zoologischen Museum in Berlin 2(3): 67-195.

Becker Th (1911) Chloropidae. Eine Monographische Studie. III. Teil. Die indo-australische

Region. Annales Historico-Naturales Musei Nationalis Hungarici 9: 35-170.

Becker Th, de Meijere JCH (1913) Chloropiden aus Java. Tijdschrift voor Entomologie 56: 283-307.

Cherian PT (1970) Descriptions of some new Chloropidae (Diptera) from India. Oriental Insects 4(4): 363-371. https://doi.org/10.1080/00305316.1970.10433972

Cherian PT (1977) The genus Siphunculina (Diptera: Chloropidae) from India. Oriental Insects 11(3): 363-368. https://doi.org/10.1080/00305316.1977.10433816

Chansang U, Mulla MS, Chantaroj S, Sawanpanyalert P (2010) The eye fly Siphunculina funicola (Diptera: Chloropidae) as a carrier of pathogenic bacteria in Thailand. The Southeast Asian Journal of Tropical Medicine and Public Health 41(1): 61-70.

Cumming JM, Wood DM (2009) Adult morphology and terminology. In: Brown BV, Borkent A, Cumming JM, Wood DM, Woodley NE, Zumbado MA (Eds) Manual of Central American Diptera. Vol. 1. NRC Research Press, Ottawa, 9-50.

Duda O (1934) Fauna sumatrensis. Bijdrage No. 74, Chloropidae (Dipt.). Tijdschrift voor Entomologie 77: 55-161.

Enderlein G (1911) Klassifikation der Oscinosominen. Sitzungsberiche der Gesellschaft naturforschender Freunde zu Berlin 1911(4): 185-244.

Ferrar P (1987) A Guide to the Breeding Habits and Immature Stages of Diptera Cyclorrhapha. Entomonograph 8, Part 1: text, 1-478.

Graham-Smith GS (1930) The Oscinidae (Diptera) as vectors of conjunctivitis, and the anatomy of their mouth parts. Parasitology 22: 457-467. https://doi.org/10.1017/ S0031182000011306

Ismay JW, Nartshuk EP (2000) A. 11. Family Chloropidae. In: Papp L, Darvas B (Eds) Contributions to a Manual of Palaearctic Diptera. Appendix Volume. Science Herald, Budapest, 387-429.

Iwasa M, Oikawa S, Kanmiya K (2013) Siphunculina quinquangula (Loew) (Diptera, Chloropidae) new to Japan: Emergence from the remains stage of pig carcass, with the implications for forensic entomology. Medical Entomology and Zoology 64(2): 103-106. https:// doi.org/10.7601/mez.64.103

Kanmiya K (1982) Two new species and three new records of the genus Siphunculina Rondani from Japan (Diptera: Chloropidae). Japanese Journal of Sanitary Zoology 33(2): 111-121. https://doi.org/10.7601/mez.33.111

Kanmiya K (1983) A systematic study of the Japanese Chloropidae (Diptera). Memoirs of the Entomological Society of Washington 11: 1-370.

Kanmiya K (1989) Study on the eye-flies, Siphunculina Rondani from the Oriental Region and Far East (Diptera, Chloropidae). Japanese Journal of Sanitary Zoology 40(suppl.): 65-86. https://doi.org/10.7601/mez.40.65_2

Kanmiya K (1994) Study on the eye-flies Siphunculina Rondani from Nepal (Diptera, Chloropidae). Japanese Journal of Sanitary Zoology 45(suppl.): 55-69. https://doi.org/10.7601/mez.45.55

de Meijere JCH (1905) Siphonella funicola n. sp., eine neue Javanische Dipteren-Art. Notes from the Leyden Museum 25: 160-162. 
de Meijere JCH (1918) Studien über südostasiatische Dipteren. XIV. Verzeichnis der von mir behandelten Arten. Tijdschrift voor Entomologie 60: 275-369.

Merz B (2008) Two new species of Chloropidae (Diptera) from Switzerland. Revue Suisse de Zoologie 115(4): 661-676. https://doi.org/10.5962/bhl.part.80452

Nartshuk EP (1984) Family Chloropidae. In: Soós A, Papp L (Eds) Catalogue of Palaearctic Diptera. Vol. 10. Clusiidae-Chloropidae. Akadémiai Kiadó, Budapest, 222-298.

Nartshuk EP (2005) Grassflies (Diptera, Chloropidae) of South Korea, with a review of species of the Genus Centorisoma Becker. Entomological Review 85(5): 555-568.

Nartshuk EP (2007) Fauna Europaea: Chloropidae. In: Pape ET (Ed.) Fauna Europaea: Diptera, Brachycera. Version 1.0 (online). http://www.faunaeur.org

Nartshuk EP (2012) A check list of the world genera of the family Chloropidae (Diptera, Cyclorrhapha, Muscomorpha). Zootaxa 3267: 1-43.

Rondani C (1856) Dipterologiae Italicae prodromus. Vol. I. Genera Italica ordinis Dipterorum ordinatum disposita et distincta et in familias et stirpes aggregata. A. Stoschi, Parmae, 228 pp. https://doi.org/10.5962/bhl.title.8160

Sabrosky CW (1977) Familiy Chloropidae. In: Delfinado MD, Hardy DE (Eds) A Catalog of Diptera of the Oriental Region, Volume 3. The University Press of Hawaii, Honolulu, 277-319.

Sabrosky CW (1980) Family Chloropidae. In: Crosskey RW (Ed.) Catalogue of the Diptera of the Afrotropical Region. British Museum (Natural History), London, 695-712.

Sabrosky CW (1989) Family Chloropidae. In: Evenhuis NL (Ed.) Catalog of the Diptera of the Australasian and Oceanian Regions. Bishop Museum Press, Honolulu, 650-665. 